OPEN ACCESS

Edited by:

Tim Bogg,

Wayne State University, USA

Reviewed by:

Peter Harms,

University of Alabama, USA

Elizabeth Austin,

University of Edinburgh, UK

*Correspondence:

Sarah K. Davis

sarah.davis@worc.ac.uk

Specialty section:

This article was submitted to

Personality and Social Psychology,

a section of the journal

Frontiers in Psychology

Received: 10 June 2016 Accepted: 18 August 2016

Published: 30 August 2016

Citation:

Davis SK and Nichols R (2016) Does Emotional Intelligence have a "Dark"

Side? A Review of the Literature.

Front. Psychol. 7:1316.

doi: 10.3389/fpsyg.2016.01316

\section{Does Emotional Intelligence have a "Dark" Side? A Review of the Literature}

\author{
Sarah K. Davis * and Rachel Nichols \\ Psychological Sciences, Institute of Health and Society, University of Worcester, Worcester, UK
}

Emotional intelligence (El) was once touted as the panacea for a satisfying and successful life. Consequently, there has been much emphasis on developing interventions to promote this personal resource in applied settings. Despite this, a growing body of research has begun to identify particular contexts when El does not appear helpful and may even be deleterious to a person, or those they have contact with, suggesting a "dark" side to the construct. This paper provides a review of emergent literature to examine when, why and how trait and ability El may contribute to negative intrapersonal (psychological ill-health; stress reactivity) and interpersonal outcomes (emotional manipulation; antisocial behavior). Negative effects were found to operate across multiple contexts (health, academic, occupational) however these were often indirect, suggesting that outcomes depend on pre-existing qualities of the person. Literature also points to the possibility of "optimal" levels of El-both within and across El constructs. Uneven profiles of self-perceptions (trait facets) or actual emotional skills contribute to poorer outcomes, particularly emotional awareness, and management. Moreover, individuals who possess high levels of skill but have lower self-perceptions of their abilities fare worse that those with more balanced profiles. Future research must now improve methodological and statistical practices to better capture El in context and the negative corollary associated with high levels.

Keywords: emotional intelligence, dark side, psychological health, stress reactivity, emotional manipulation, deception, dark triad, antisocial behavior

\section{INTRODUCTION}

Emotional intelligence (EI) is broadly defined as competency in perceiving, understanding and regulating our own emotions and the emotions of others (Zeidner et al., 2009). Two perspectives permeate the literature, trait EI (TEI: emotion relevant self-perceptions and dispositions e.g., empathy, self-control) and ability EI (AEI: cognitive abilities specialized for emotional information processing e.g., emotion perception, understanding), which are distinct in their measurement methods and underlying empirical bases (Petrides et al., 2007; Mayer et al., 2008). It was once argued that high levels of EI could be more beneficial for success than known predictors of performance, particularly intelligence (Goleman, 1995). Myriad Social and Emotional Learning programmes (SEL) and adult training packages were consequently developed and implemented in educational (e.g., Brackett et al., 2012) and workplace settings (e.g., Grant, 2007), with the goal of enhancing these emotional self-perceptions and skills for successful adjustment. 
Over the past two decades, research has supported a link between EI and adaptive life outcomes, including better mental and physical health (Martins et al., 2010), academic (Perera and DiGiacomo, 2013), and occupational success (Joseph and Newman, 2010). Nevertheless, with statistical control for allied performance factors (e.g., personality; IQ), many of these effects are not of the original size and strength predicted by early EI proponents (Matthews et al., 2012). Moreover, whilst evaluations of SEL training programmes have revealed benefits for mental health, pro-social behavior and academic achievement, effects are typically moderate in size and of questionable longevity (Durlak et al., 2011). Thus, whilst EI appears to contribute some adaptive value to life outcomes, the original fervor for the construct has been tempered.

Simultaneously, a growing body of research has begun to identify particular contexts when EI does not appear helpful, and even deleterious to a person, or those they have contact with, suggesting there is a "dark" side to the construct. For instance, high levels of AEI conferred vulnerability for internalizing symptoms in adults facing chronic stress (Ciarrochi et al., 2002), whilst in occupational settings, EI was used as a tool for emotional manipulation of others (Côté et al., 2011). The concept of dark traits and abilities is not new. There is a rich literature examining prototypically negative personality traits-Machiavellianism; Psychopathy; Narcissism which are characterized by callous and manipulative behaviors and frequently linked to nefarious antisocial outcomes (Furnham et al., 2013). Indeed, some research has reported positive associations between high TEI and Narcissism (e.g., Petrides et al., 2011; Zhang et al., 2015), indicating that similar antisocial outcomes may befit high TEI scorers. Grant and Schwartz (2011) postulate even prototypically positive skills and virtues, e.g., loyalty and empathy, can have decreasing returns at increasing levels - at very high levels, any personal benefits are outweighed by a negative impact on adjustment ("nonmonotonic" effects). This is well-documented in the case of self-esteem which has been associated with better academic, psychological, and social adjustment (Zeigler-Hill et al., 2016), yet there is ample evidence that highly inflated (and unstable) levels of selfesteem can have negative consequences, including aggression (for review see Baumeister et al., 2003). A similar pattern has been documented for self-efficacy-confidence in one's ability to meet challenges and achieve goals (Ehrlinger and Eichenbaum, 2016). For instance, self-effacing (under-confidence in cognitive abilities) and self-enhancing (over-confidence in abilities) beliefs resulted in increased depression and higher levels of dejectionrelated emotion in students following inconsistent performance feedback (Kim and Chiu, 2011). This provides support for the idea of an "optimal" level for such positive illusions (e.g., Baumeister, 1989).

There is therefore theoretical and empirical support for dark EI. As a multifaceted construct embodying skills (AEI), selfperceptions, and dispositions (TEI) relating to self and others (e.g., assertiveness; emotion management), very high levels of EI could convey negative internal or "intrapersonal" effects for the person concerned, but also negative external or "interpersonal" effects involving others. Following a timely review of the literature, this paper seeks to explore these possibilities further by addressing the following questions: When (in which contexts), why (which facets), and how (directly or indirectly) might EI be deleterious or harmful? Is there an optimal level of EI? Hence, this review aims to synthesize a growing number of findings which do not fit with the dominant empirical position that higher EI is always better.

English language empirical studies, published in peerreviewed journals since 1990, were retrieved via PsycInfo and ScienceDirect. Keywords included emotional intelligence, negative effect, deleterious, damaging, harmful, disadvantage. Only studies using validated measures of T/AEI, derived from established models of EI (see Table 1 for exemplars) and those that reported statistically significant relationships between EI and outcome variables, were included. After removing duplicates, reviewing titles, and abstracts, 38 studies were retained from an initial pool of 308. 24 of these met all above-mentioned inclusion criteria upon reading in full. The 14 studies excluded at this stage alluded to but did not report statistically significant detrimental effects related to EI (e.g., Balluerka et al., 2013). A further 10 articles were added from a manual search of the reference list of each study retrieved, producing a final set of 34 articles. Studies were coded for reference information, methodological details (EI tool/sample demographics), and key findings. Outcome variables were classified as being either "intrapersonal" (e.g., mental health status) or "interpersonal” (e.g., deviant behavior) in nature (see Table 1).

\section{INTRAPERSONAL EFFECTS}

Emotionally intelligent individuals should be adept at coping with the demands of everyday life (Bar-On, 2006) with competent affect regulation seen as crucial for psychological wellbeing (Mayer and Salovey, 1997). This skill is supported by lower order EI abilities (perceiving; using emotion to facilitate thinking; understanding emotion), which contribute to a fundamental emotional awareness necessary for adaptive emotion management. It is argued that beliefs about emotional abilities (indicated by TEI) are just as important, given appraisal and reactivity to everyday activities may be partly filtered through these (Petrides et al., 2007). Whilst there is evidence to link EI to better mental and physical health (for reviews see Martins et al., 2010; Resurreccion et al., 2014), research suggests that in some contexts, high levels of EI (particularly emotional awareness; management) may be related to poorer psychological health and adversely impact upon an individual's capacity to deal with emotionally salient situations.

\section{Psychological (III) Health}

Most studies utilized measures of TEI, particularly the Trait Meta-Mood Scale-a multidimensional assessment of mood awareness. For example, attention to emotions was positively associated with greater negative emotional impact (annoyance; dejection) in victims of cyber-bullying (Elipe et al., 2015) and higher levels of symptomatology in patients with borderline personality or anxiety disorders (Lizeretti et al., 2012). Moreover, both studies propose that an imbalance in constituent 


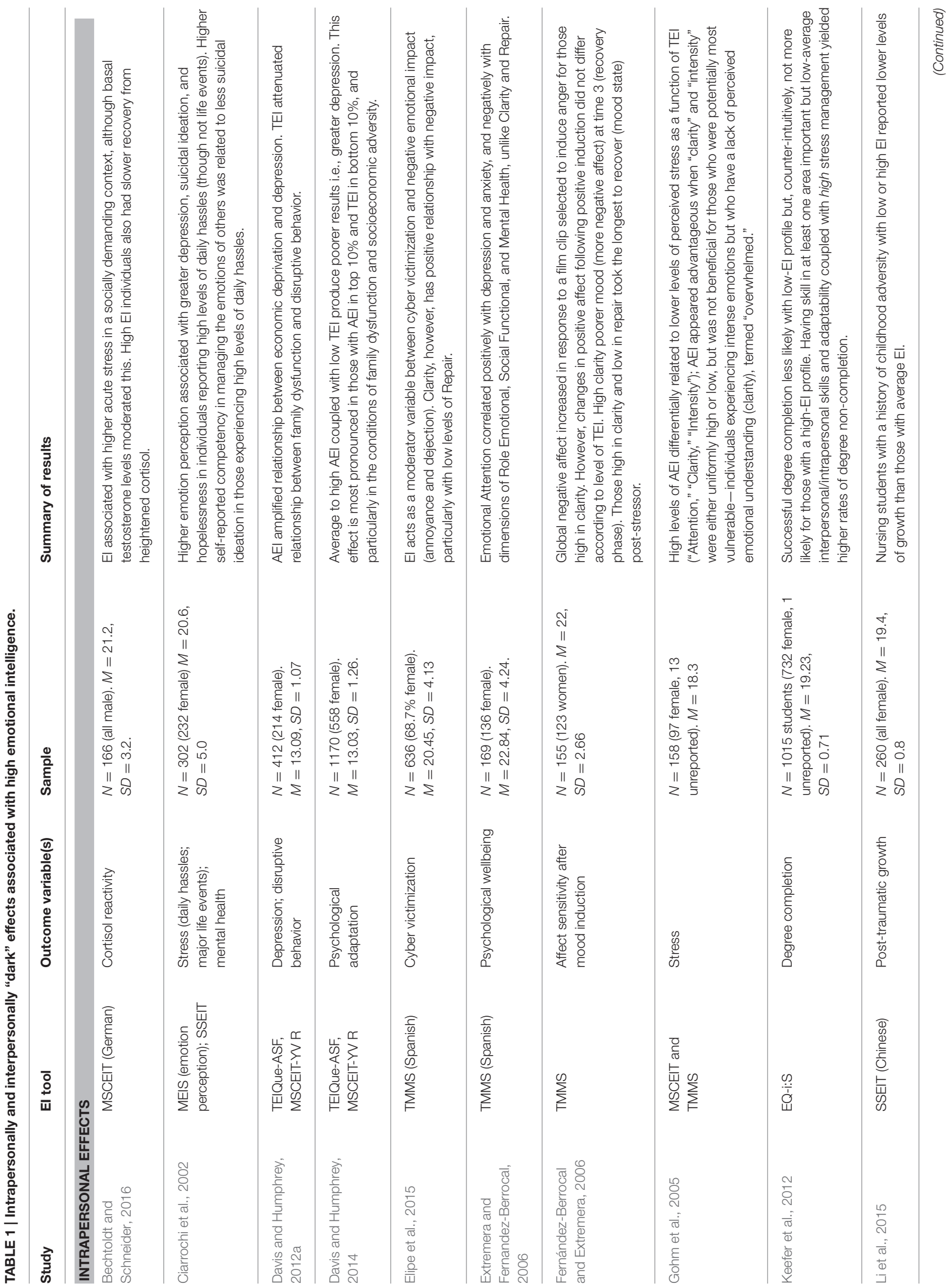




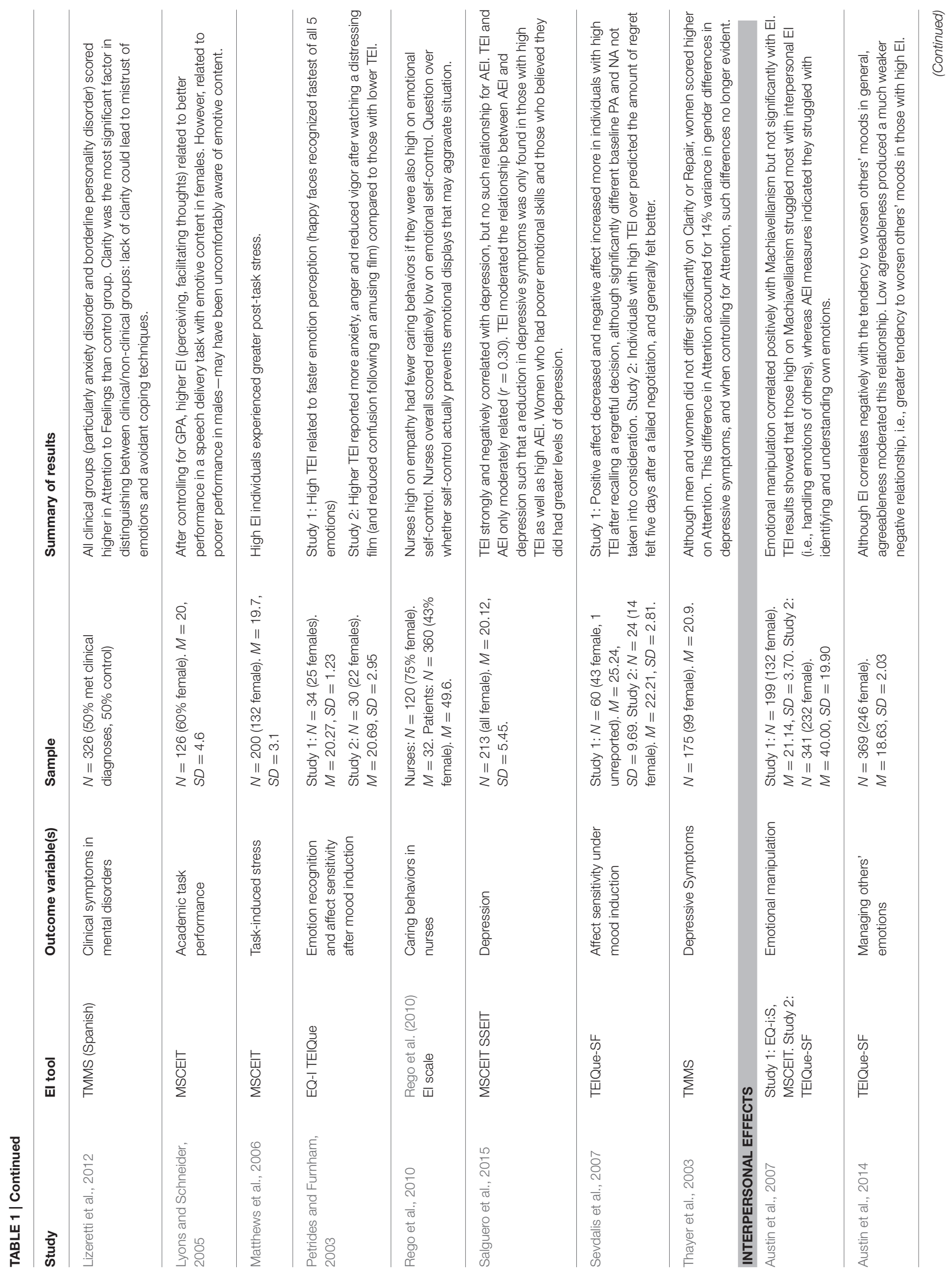




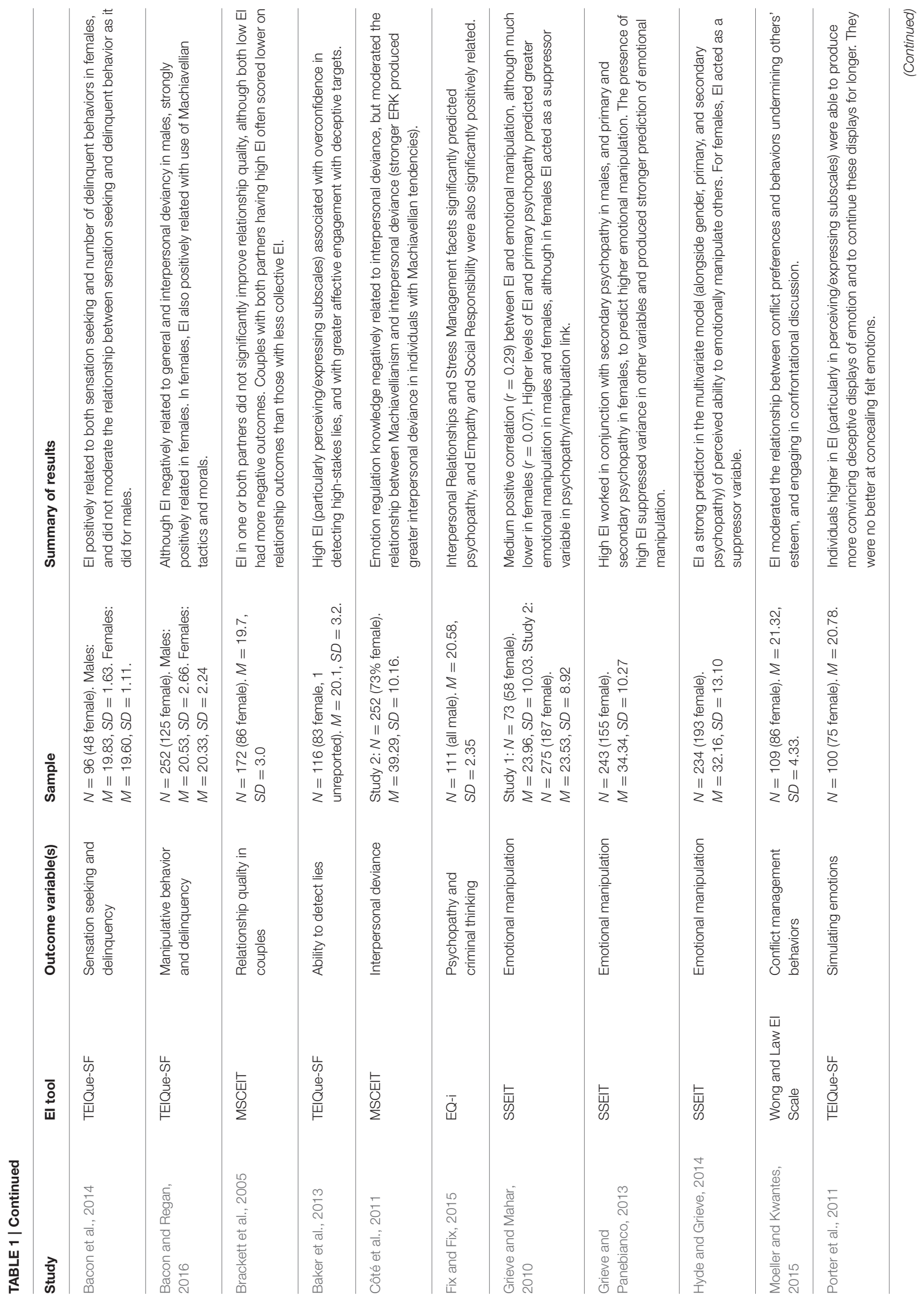


components of TEI may characterize vulnerability, i.e., an excessive awareness of (negative) emotions coupled with a lack of competency to repair these emotional states resulted in greater psychological discomfort. Extremera and Fernandez-Berrocal (2006) found the same TEI profile predicted mood disorders in young people suggesting this may underpin ruminative thinking known to prolong depressed mood. This appears particularly true in females, where greater attention to emotions accounted entirely for sex differences in depressive symptoms (Thayer et al., 2003).

Explanatory pathways appear less straightforward with regard to AEI. Higher levels of emotional skill have been found to amplify the effects of chronic stressors (socio-economic adversity; daily hassles) on depression, hopelessness and suicidal ideation (Ciarrochi et al., 2002; Davis and Humphrey, 2012b). In Ciarrochi et al.'s study this effect was restricted to skill in emotion perception leading the authors to speculate that a "hyper-awareness" of negative emotion-laden situations may contribute to mental ill health. To corroborate this trend, AEI related to fewer stress symptoms when self-perceived emotional clarity and attention were either uniformly high or low, but was not beneficial for individuals experiencing intense emotions who reported a lack of emotional understanding (Gohm et al., 2005). It may also be the case that TEI and AEI work in tandem to reinforce these effects; high levels of emotional skill yet low emotional self-efficacy, result in higher levels of depression in adolescent and adults (Davis and Humphrey, 2014; Salguero et al., 2015).

\section{Stress (Over) Reactivity}

Possible mechanisms of heightened emotional sensitivity may lie in the relationship between EI and stress reactivity. Although those with higher level of TEI show minimal mood deterioration, heart rate variation, and cortisol release in response to stressors (Mikolajczak et al., 2007; Laborde et al., 2011), AEI appears to be positively related to greater cortisol reactivity and slower recovery from situational (lab-induced) social stress-particularly in those with high ability to perceive threat-related emotions (Bechtoldt and Schneider, 2016). Enhanced reactivity has also been documented via subjective reports of mood changethose with high AEI reported an increase in post-task distress, despite reduced pre-task levels, compared to those lower in AEI (Matthews et al., 2006). Mood induction studies have shown that there are also instances where TEI may contribute to greater self-reported mood deterioration (less positive and greater negative affect) following exposure to negative mood manipulation (Petrides and Furnham, 2003; Fernández-Berrocal and Extremera, 2006, study 2; Sevdalis et al., 2007, study 1).

Detrimental effects have been similarly demonstrated in stressful or high-stakes applied settings. For male (not female) students, high levels of emotion perception and management related to poorer delivery of a timed speech to an audience, possibly due to a hyper-awareness of emotional reactivity to a contentious topic (sexual harassment) and the need to control this response (Lyons and Schneider, 2005). University students with uniformly high or average TEI profiles appear more likely to graduate compared to those with an "uneven" pattern of skills; 
low-average interpersonal/intrapersonal skills and adaptability coupled with high stress management yielded higher rates of degree non-completion (Keefer et al., 2012). In a similar vein, high TEI nursing students fared no better than those with very low levels in terms of experiencing post-traumatic growth following exposure to childhood adversity-average levels of EI were most beneficial (Li et al., 2015). Moreover, nurses appear to decrease caring behaviors toward their patients, despite high empathy levels, if they also have high TEI self-control (Rego et al., 2010). It may be the case that these "over-controlled" individuals are unwilling to translate knowledge (empathic concern) into practice for reasons of personal safeguarding (i.e., compassion fatigue). Recent research hints at the complexity involved in this relationship (Zeidner et al., 2013) and clearly further research is required in applied settings to verify the adaptive nature of EI. Nevertheless, research alludes to the notion of an optimal balance between emotional sensitivity and management for successful adaptation.

\section{INTERPERSONAL EFFECTS}

High TEI typically reflects extroverted (happy; optimistic), agreeable (low assertiveness), conscientious (self-motivated), confident, and emotionally stable individuals (Petrides, 2009). High levels of AEI reflect superior emotional knowledge, awareness, and regulatory ability. Both types of EI therefore subsume tools and qualities that appear useful for successful navigation of social exchanges. Whilst high EI has been associated with more satisfying relationships and pro-social behaviors (e.g., Lopes et al., 2004; Frederickson et al., 2012), a growing pool of studies suggest that EI may be used as a tool for manipulative ends, with high scorers skilled in emotional distortion and antisocial behaviors. This may result in adaptive accomplishment of personal self-serving goals but may also thwart the development of satisfying interpersonal relationships. For instance, within a romantic relationship, one partner having high TEI appears to improve relationship quality, yet two high scorers relates to poorer outcomes-possibly due to competitive over-management of the relationship, or an acute awareness of emotional idiosyncrasies (Brackett et al., 2005). This section reviews evidence linking high EI to emotional manipulation and antisocial behaviors (e.g., aggression, deviance).

\section{Emotional Manipulation and Deception}

Direct associations between A/TEI and emotional manipulation are inconsistent-either moderately positive or absent (Austin et al., 2007; Grieve and Mahar, 2010; Grieve and Panebianco, 2013). So too are correlations between facets of psychopathy (sensation-seeking, fearlessness, aggression), AEI and TEI-with some suggesting that skill in using emotion, stress management, and interpersonal interaction are predictive of psychopathy (Vidal et al., 2010; Fix and Fix, 2015) whilst others find no relationship (Lishner et al., 2011). There is, however, converging evidence to suggest that EI operates indirectly, in conjunction with allied traits and skills, to predict manipulative behaviors. Grieve and Panebianco (2013) found that males with higher levels of TEI, social information processing, indirect aggression, and self-serving cognitive distortions were more likely to exploit others. This pattern varied according to sex, with age, primary psychopathic traits, and social awareness being additionally important predictors of manipulation in females. Grieve and Mahar (2010) found similar multi-facetted sex differenceswhilst primary psychopathy and high levels of TEI conjointly predicted emotional manipulation for both males and females, ethical reasoning and secondary psychopathy were important correlates for females only. The predictive effect of high levels of psychopathic traits/TEI on manipulative behavior was replicated again more recently (Hyde and Grieve, 2014). Consequently, the way in which EI is deployed (i.e., for better or worse) appears contingent upon other underlying pre-dispositions and competencies of the individual.

This manipulative ability may, in part, be underscored by a natural capacity deceive. Analysis of self-report data showed that those with high TEI and cognitive ability were more likely to fake on high stakes measures (Tett et al., 2012). Objectively, Porter et al. (2011) found that high TEI emotionality (perceiving and expressing emotion) was related to an increased ability to simulate deceptive emotions and to persist in these displays for longer. Conversely, those high in TEI wellbeing (happiness; optimism) were no better at masking their true felt emotions, suggesting an association between TEI and a tendency toward emotional openness. This perhaps explains why high TEI (emotionality) is associated with a propensity for gullibility and overestimation of others' honesty (Baker et al., 2013).

\section{Antisocial Behavior}

Austin et al. (2014) found trait agreeableness mediated the relationship between TEI and use of non-prosocial behaviors (e.g., worsening others' moods), such that at low levels of agreeableness, those high in TEI were prone to such behavior. AEI may also moderate antisocial behaviors. Côté et al. (2011) found that whilst skill in emotion management was not directly related to interpersonal deviance, it served to intensify the relationship between Machiavellianism and deviance, acting as a useful tool for those with a propensity to harm. Similarly TEI emotion management and understanding increase the tendency to engage in confrontation in those who view this as an effective negotiation strategy (Moeller and Kwantes, 2015). This selfserving element of EI could therefore present as selfish and aggressive behavior toward others. Sex differences are also evident with high TEI reducing Machiavellian tactics, moral thinking, and delinquency in males, yet promoting all of these aspects in females (Bacon and Regan, 2016) who may rely more on emotive, relational forms of aggression, and manipulation (Bacon et al., 2014).

\section{DISCUSSION}

This review finds embryonic support for the notion of "dark" EI. There are contexts in which it is not universally beneficial to have high levels of EI-whether trait or ability. This can translate into negative effects for self (psychological ill-health; stress reactivity) and/or others (manipulative, antisocial behaviors; see thematic overview: Figure 1). Whilst prevailing EI literature 

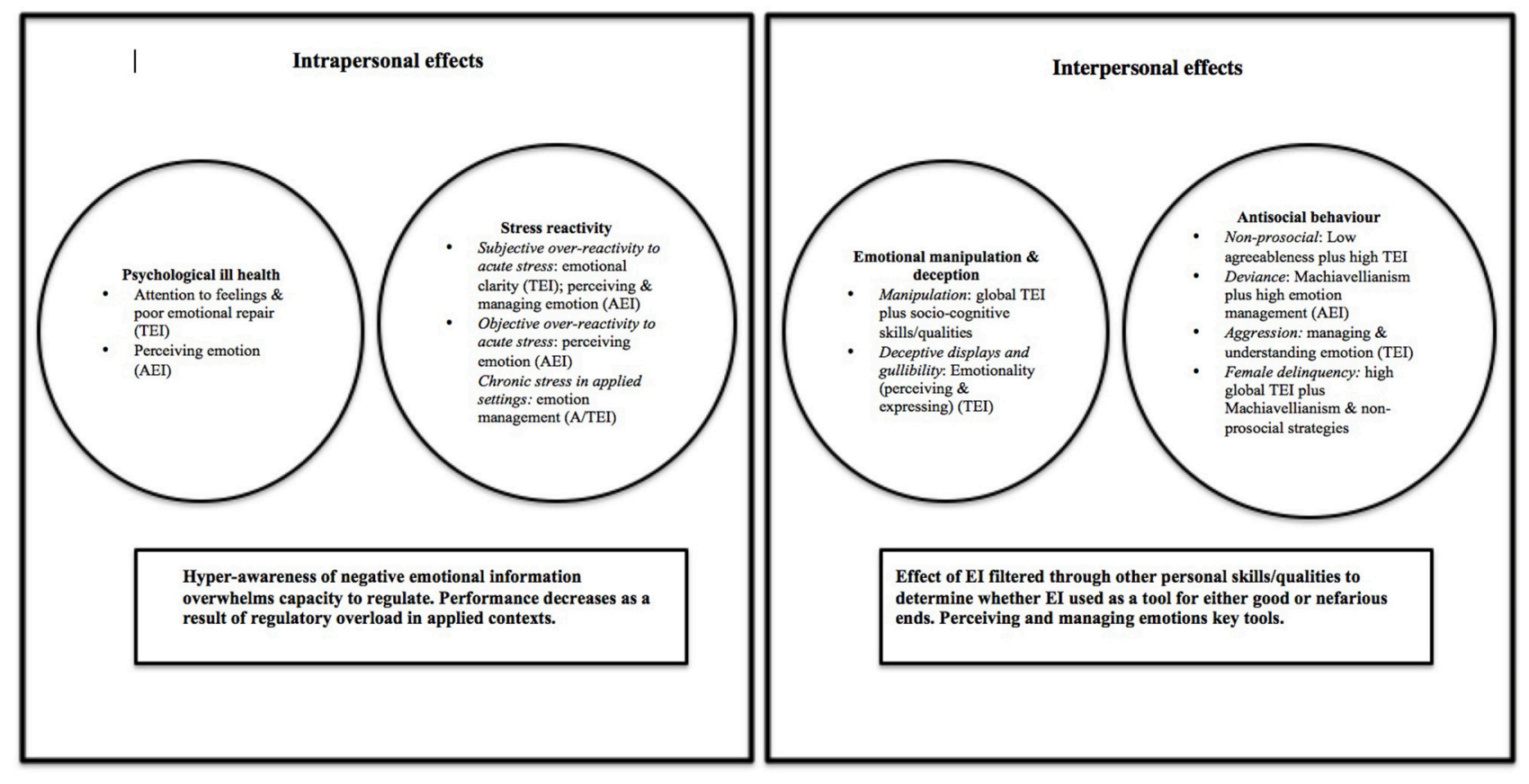

FIGURE 1 | Summary of emergent "dark" El themes.

discusses positive effects of possessing high EI in intrapersonal and interpersonal domains (e.g., Joseph and Newman, 2010; Martins et al., 2010), this review synthesizes a growing number of anomalous findings that do not concur with this perspective. A number of key themes emerged concerning when, why and how might EI be deleterious or harmful.

Dark effects spanned multiple environmental contexts (academic; health; occupational) across intrapersonal and interpersonal functioning. There was a trend toward individuallevel contextual effects, with sex differences evident in psychological health, stress reactivity, emotional manipulation, and delinquency. Across both A/TEI domains, emotion management, and perception were most often implicated in negative outcomes. However, profiles of within-person vulnerability exist, particularly for intrapersonal outcomes, suggesting a balance between EI facets is optimal for adaptation. For instance, high emotional awareness, low regulation, and/or understanding relates to sub-clinical symptomatology (e.g., Gohm et al., 2005; Extremera and Fernandez-Berrocal, 2006). It is important that EI researchers move away from traditional bivariate methods to use person-centered analytical techniques (e.g., latent profile analysis) to allow further scrutiny of multi-facetted EI in action (Keefer et al., 2012). A profile of cross-construct within-person vulnerability may also exist. Whilst few studies have examined this possibility by including multiple measures of EI, having high levels of emotional skill (AEI) and low emotional self-confidence (TEI) to translate skills into practice, appears deleterious (Davis and Humphrey, 2014). Hence there could be an optimal level at which each type of EI is useful before effects become negative. Finally, EI operated indirectly to modify or jointly predict dark effects via underlying socio-cognitive skills/qualities (e.g., agreeableness; cognitive ability) and environmental contexts (e.g., stress). There is therefore an urgent need to study "EI in action" by modeling moderating and mediating effects to better understand how and when EI is deployed. For instance, findings suggest that deleterious intrapersonal effects (e.g., poor mental health) could stem from hypersensitivity to emotional information, which manifests in particular stressful situations (e.g., socioeconomic adversity; public speaking). Researchers must examine why this arises; for instance, do those with high levels of emotional skill show differing patterns of attentional bias for threatening emotional information when under stress? Does this apply to all types of stress or is this selective? How does this relate to different intra and interpersonal outcomes in particular groups (e.g., clinical, academic, occupational)? It is possible that a hyperawareness of emotional cues/consequences conveys interpersonal advantages in competitive job roles where climbing the social hierarchy is rewarded (contingent perhaps on possessing other key traits/abilities e.g., high cognitive ability).

The relatively small pool of literature, disparate range of EI tools utilized and unsophisticated analytical methods make it difficult to identify precisely what optimal EI might be and in which context this might arise. So far, average EI levels appear most beneficial for adaptation (e.g., Li et al., 2015), and individuals with low to average levels gain the most from training interventions (Keefer et al., 2012). Methodological techniques for the study of non-monotonic effects should now be routinely applied to EI research to aid this endeavor (for examples see Davis and Humphrey, 2012a; Li et al., 2015). Researchers must 
examine EI in context (multivariable models; curvilinear trends; indirect pathways; measure of "impact") and control for the overlapping influence of allied personality traits (Veselka et al., 2012). This is important for construct coherency e.g., impulse control/self-regulatory behavior is indicated by measures of emotion manipulation, "Big Five," and EI. Additionally, the lack of longitudinal research makes it challenging to determine how deleterious outcomes might present developmentally, whether they are long lasting and ultimately, whether training EI is beneficial.

\section{REFERENCES}

Austin, E. J., Farrelly, D., Black, C., and Moore, H. (2007). Emotional intelligence, Machiavellianism and emotional manipulation: does EI have a dark side? Pers. Individ. Dif. 43, 179-189. doi: 10.1016/j.paid.2006.11.019

Austin, E. J., Saklofske, D. H., Smith, M., and Tohver, G. (2014). Associations of the managing the emotions of others (MEOS) scale with personality, the Dark Triad and trait EI. Pers. Individ. Dif. 65, 8-13. doi: 10.1016/j.paid.2014.01.060

Bacon, A. M., Burak, H., and Rann, J. (2014). Sex differences in the relationship between sensation seeking, trait emotional intelligence and delinquent behaviour. J. Forens. Psychiatry Psychol. 25, 673-683. doi: 10.1080/14789 949.2014.943796

Bacon, A. M., and Regan, L. (2016). Manipulative relational behaviour and delinquency: sex differences and links with emotional intelligence. J. Forens. Psychiatry Psychol. 27, 331-348. doi: 10.1080/14789949.2015.1134625

Baker, A., ten Brinke, L., and Porter, S. (2013). Will get fooled again: emotionally intelligent people are easily duped by high-stakes deceivers. Legal Criminol. Psychol. 18, 300-313. doi: 10.1111/j.2044-8333.2012.02054.x

Balluerka, N., Aritzeta, A., Gorostiaga, A., Gartzia, L., and Soroa, G. (2013). Emotional intelligence and depressed mood in adolescence: a multilevel approach. Int. J. Clin. Health Psychol. 13, 110-117. doi: 10.1016/S1697-2600(13) 70014-0

Bar-On, R. (2006). The Bar-On model of emotional-social intelligence (ESI). Psicothema 18, 13-25.

Baumeister, R. F. (1989). The optimal margin of illusion. J. Soc. Clin. Psychol. 8, 176-189. doi: 10.1521/jscp.1989.8.2.176

Baumeister, R. F., Campbell, J. D., Krueger, J. I., and Vohs, K. D. (2003). Does high self-esteem cause better performance, interpersonal success, happiness, or healthier lifestyles? Psycholo. Sci. Public Interest 4, 1-44. doi: 10.1111/15291006.01431

Bechtoldt, M. N., and Schneider, V. K. (2016). Predicting stress from the ability to eavesdrop on feelings: emotional intelligence and testosterone jointly predict cortisol reactivity. Emotion. doi: 10.1037/emo0000134. [Epub ahead of print].

Brackett, M., Rivers, S. E., Reyes, M. R., and Salovey, P. (2012). Enhancing academic performance and social and emotional competence with the RULER feeling words curriculum. Learn. Individ. Differ. 22, 218-224. doi: 10.1016/ j.lindif.2010.10.002

Brackett, M., Warner, R. M., and Bosco, J. S. (2005). Emotional intelligence and relationship quality among couples. Pers. Relatsh. 12, 197-212. doi: 10.1111/ j.1350-4126.2005.00111.x

Ciarrochi, J., Dean, F. P., and Anderson, S. (2002). Emotional intelligence moderates the relationship between stress and mental health. Pers. Individ. Dif. 32, 197-209. doi: 10.1016/S0191-8869(01)00012-5

Côté, S., DeCelles, K. A., McCarthy, J. M., Van Kleef, G. A., and Hideg, I. (2011). The Jekyll and Hyde of Emotional Intelligence. Psychol. Sci. 22, 1073-1080. doi: $10.1177 / 0956797611416251$

Davis, S. K., and Humphrey, N. (2012a). Emotional intelligence as a moderator of stressor - mental health relations in adolescence: evidence for specificity. Pers. Individ. Dif. 52, 100-105. doi: 10.1016/j.paid.2011.09.006

Davis, S. K., and Humphrey, N. (2012b). The influence of emotional intelligence (EI) on coping and mental health in adolescence: divergent roles for trait and ability EI. J. Adolesc. 35, 1369-1379. doi: 10.1016/j.adolescence.2012. 05.007

\section{AUTHOR CONTRIBUTIONS}

Substantial contributions to the conception or design of the work (SD); or the acquisition, analysis, or interpretation of data for the work (SD/RN); Drafting the work or revising it critically for important intellectual content $(\mathrm{SD} / \mathrm{RN})$; Final approval of the version to be published (SD/RN). Agreement to be accountable for all aspects of the work in ensuring that questions related to the accuracy or integrity of any part of the work are appropriately investigated and resolved $(\mathrm{SD} / \mathrm{RN})$.

Davis, S. K., and Humphrey, N. (2014). Ability versus trait emotional intelligence: dual influences on adolescent psychological adaptation. J. Individ. Dif. 35, 54-62. doi: 10.1027/1614-0001/a000127

Durlak, J. A., Weissberg, R. P., Dymnicki, A. B., Taylor, R. D., and Schellinger, K. B. (2011). The impact of enhancing students' social and emotional learning: a meta-analysis of school-based universal interventions. Child Dev. 82, 405-432. doi: 10.1111/j.1467-8624.2010.01564.x

Ehrlinger, J., and Eichenbaum, A. (2016). "The dark (and light) sides of overconfidence," in The Dark Side of Personality: Science and Practice in Social, Personality, and Clinical Psychology, eds V. Zeigler-Hill and D. K. Marcus (Washington DC, US: American Psychological Association), 251-266.

Elipe, P., Mora-Merchán, J. A., Ortega-Ruiz, R., and Casas, J. A. (2015). Perceived emotional intelligence as a moderator variable between cybervictimization and its emotional impact. Front. Psychol. 6:486. doi: 10.3389/fpsyg.2015. 00486

Extremera, N., and Fernández-Berrocal, P. (2006). Emotional intelligence as predictor of mental, social, and physical health in university students. Span. J. Psychol. 9, 45-51. doi: 10.1017/S1138741600005965

Fernández-Berrocal, P., and Extremera, N. (2006). Emotional intelligence and emotional reactivity and recovery in laboratory context. Psicothema 18, $72-78$.

Fix, R. L., and Fix, S. T. (2015). Trait psychopathy, emotional intelligence, and criminal thinking: predicting illegal behavior among college students. Int. J. Law Psychiatry 42, 183-188. doi: 10.1016/j.ijlp.2015. 08.024

Frederickson, N., Petrides, K. V., and Simmonds, E. (2012). Trait emotional intelligence as a predictor of socioemotional outcomes in early adolescence. Pers. Individ. Dif. 52, 323-328. doi: 10.1016/j.paid.2011.10.034

Furnham, A., Richards, S. C., and Paulhus, D. L. (2013). The Dark Triad of personality: a 10 year review. Soc. Personal. Psychol. Compass 7, 199-216. doi: $10.1111 /$ spc3.12018

Gohm, C. L., Corser, G. C., and Dalsky, D. J. (2005). Emotional intelligence under stress: useful, unnecessary, or irrelevant? Pers. Individ. Dif. 39, 1017-1028. doi: 10.1016/j.paid.2005.03.018

Goleman, D. (1995). Emotional Intelligence. New York, NY: Bantam Books.

Grant, A. M. (2007). Enhancing coaching skills and emotional intelligence through training. Indus. Commercial Train. 39, 257-266. doi: 10.1108/001978 50710761945

Grant, A. M., and Schwartz, B. (2011). Too much of a good thing: the challenge and opportunity of the inverted U. Pers. Psychol. Sci. 6, 61-76. doi: 10.1177/17456 91610393523

Grieve, R., and Mahar, D. (2010). The emotional manipulation, psychopathy nexus: relationships with emotional intelligence, alexithymia and ethical position. Pers. Individ. Dif. 48, 945-950. doi: 10.1016/j.paid.2010.02.028

Grieve, R., and Panebianco, L. (2013). Assessing the role of aggression, empathy, and self-serving cognitive distortions in trait emotional manipulation. Aust. J. Psychol. 65, 79-88. doi: 10.1111/j.1742-9536.2012.00059.x

Hyde, J., and Grieve, R. (2014). Able and willing: refining the measurement of emotional manipulation. Pers. Individ. Dif. 64, 131-134. doi: 10.1016/j.paid. 2014.02.036

Joseph, D. L., and Newman, D. A. (2010). Emotional intelligence: an integrative meta-analysis and cascading model. J. Appl. Psychol. 95, 54-78. doi: 10.1037/ a0017286 
Keefer, K. V., Parker, J. D. A., and Wood, L. M. (2012). Trait emotional intelligence and University Graduation outcomes. J. Psychoeduc. Assess. 30, 402-413. doi: $10.1177 / 0734282912449446$

Kim, Y.-H., and Chiu, C.-Y. (2011). Emotional costs of inaccurate self-assessments: both self-effacement and self-enhancement can lead to dejection. Emotion 11, 1096-1104. doi: 10.1037/a0025478

Laborde, S., Brüll, A., Weber, J., and Anders, L. S. (2011). Trait emotional intelligence in sports: a protective role against stress through heart rate variability? Pers. Individ. Dif. 51, 23-27.

Li, Y., Cao, F., Cao, D., and Liu, J. (2015). Nursing students' post-traumatic growth, emotional intelligence and psychological resilience. J. Psychiatr. Ment. Health Nurs. 22, 326-332. doi: 10.1111/jpm.12192

Lishner, D. A., Swim, E. R., Hong, P. Y., and Vitacco, M. J. (2011). Psychopathy and ability emotional intelligence: widespread or limited association among facets? Pers. Individ. Dif. 50, 1029-1033. doi: 10.1016/j.paid.2011.01.018

Lizeretti, N. P., Extremera, N., and Rodríguez, A. (2012). Perceived emotional intelligence and clinical symptoms in mental disorders. Psychiatric Q. 83, 407-418. doi: 10.1007/s11126-012-9211-9

Lopes, P. N., Brackett, M. A., Nezlek, J. B., Schutz, A., Sellin, I., and Salovey, P. (2004). Emotional intelligence and social interaction. Pers. Soc. Psychol. Bull. 30, 1018-1034. doi: 10.1177/0146167204264762

Lyons, J. B., and Schneider, T. R. (2005). The influence of emotional intelligence on performance. Pers. Individ. Dif. 39, 693-703. doi: 10.1016/j.paid.2005.02.018

Martins, A., Ramalho, N., and Morin, E. (2010). A comprehensive meta-analysis of the relationship between emotional intelligence and health. Pers. Individ. Dif. 49, 554-564. doi: 10.1016/j.paid.2010.05.029

Matthews, G., Emo, A. K., Funke, G., Zeidner, M., Roberts, R. D., Costa, J. P. T., et al. (2006). Emotional intelligence, personality, and task-induced stress. J. Exp. Psychol. Appl. 12, 96-107. doi: 10.1037/1076-898x.12.2.96

Matthews, G., Zeidner, M., and Roberts, R. D. (2012). Emotional intelligence: a promise unfulfilled? Jpn. Psychol. Res. 54, 105-127. doi: 10.1111/j.1468-5884. 2011.00502.x

Mayer, J. D., Roberts, R. D., and Barsade, S. G. (2008). Human abilities: emotional intelligence. Annu. Rev. Psychol. 59, 507-536. doi: 10.1146/annurev.psych. 59.103006.093646

Mayer, J. D., and Salovey, P. (1997). “What is emotional intelligence?," in Emotional Development and Emotional Intelligence: Educational Implications, eds P. Salovey and D. Sluyter (New York, NY: Perseus Books Group), 3-31.

Mikolajczak, M., Roy, E., Luminet, O., Fillée, C., and de Timary, P. (2007). The moderating impact of emotional intelligence on free cortisol responses to stress. Psychoneuroendocrinology 32, 1000-1012. doi: 10.1016/j.psyneuen.2007.07.009

Moeller, C., and Kwantes, C. T. (2015). Too much of a good thing? Emotional intelligence and interpersonal conflict behaviors. J. Soc. Psychol. 155, 314-324. doi: $10.1080 / 00224545.2015 .1007029$

Perera, H. N., and DiGiacomo, M. (2013). The relationship of trait emotional intelligence with academic performance: a meta-analytic review. Learn. Individ. Dif. 28, 20-33. doi: 10.1016/j.lindif.2013.08.002

Petrides, K. V. (2009). "Psychometric properties of the Trait Emotional Intelligence Questionnaire (TEIQue)," in Assessing Emotional Intelligence: Theory, Research and Application, eds C. Stough, D. H. Saklofske, and J. D. A. Parker (New York, NY: Springer), 85-101.

Petrides, K. V., and Furnham, A. (2003). Trait emotional intelligence: behavioural validation in two studies of emotion recognition and reactivity to mood induction. Eur. J. Pers. 17, 39-57. doi: 10.1002/per.466

Petrides, K. V., Pita, R., and Kokkinaki, F. (2007). The location of trait emotional intelligence in personality factor space. Br. J. Psychol. 98, 273-289. doi: 10.1348/ 000712606X120618

Petrides, K. V., Vernon, P. A., Schermer, J. A., and Veselka, L. (2011). Trait emotional intelligence and the dark triad traits of personality. Twin Res. Hum. Genet. 14, 35-41. doi: 10.1375/twin.14.1.35
Porter, S., ten Brinke, L., Baker, A., and Wallace, B. (2011). Would I lie to you? "Leakage" in deceptive facial expressions relates to psychopathy and emotional intelligence. Pers. Individ. Dif. 51, 133-137. doi: 10.1016/j.paid.2011. 03.031

Puglia, M. L., Stough, C., Carter, J. D., and Joseph, M. (2005). The emotional intelligence of adult sex offenders: ability based EI assessment. J. sex. aggress. 11, 249-258. doi: 10.1080/13552600500271384

Rego, A. N., Godinho, L., McQueen, A., and Cunha, M. P. (2010). Emotional intelligence and caring behaviour in nursing. Service Ind. J. 30, 1419-1437. doi: 10.1080/02642060802621486

Resurreccion, D. M., Salguero, J. M., and Ruiz-Aranda, D. (2014). Emotional intelligence and psychological maladjustment in adolescence: a systematic review. J. Adolesc. 37, 461-472. doi: 10.1016/j.adolescence.2014. 03.012

Salguero, J., Extremera, N., Cabello, R., and Fernandez-Berrocal, P. (2015). If you have high Emotional Intelligence (EI), you must trust in your abilities the interaction effect of ability EI and perceived EI on depression in women. J. Psychoeduc. Assess. 33, 46-56. doi: 10.1177/0734282914550384

Sevdalis, N., Petrides, K. V., and Harvey, N. (2007). Trait emotional intelligence and decision-related emotions. Pers. Individ. Dif. 42, 1347-1358. doi: 10.1016/j.paid.2006.10.012

Tett, R. P., Freund, K. A., Christiansen, N. D., Fox, K. E., and Coaster, J. (2012). Faking on self-report emotional intelligence and personality tests: effects of faking opportunity, cognitive ability, and job type. Pers. Individ. Dif. 52, 195-201. doi: 10.1016/j.paid.2011.10.017

Thayer, J. F., Rossy, L. A., Ruiz-Padial, E., and Johnsen, B. H. (2003). Gender differences in the relationship between emotional regulation and depressive symptoms. Cognit. Ther. Res. 27, 349-364. doi: 10.1023/A:10239226 18287

Veselka, L., Schermer, J. A., and Vernon, P. A. (2012). The Dark Triad and an expanded framework of personality. Pers. Individ. Dif. 53, 417-425. doi: 10.1016/j.paid.2012.01.002

Vidal, S., Skeem, J., and Camp, J. (2010). Emotional intelligence: painting different paths for low-anxious and high-anxious psychopathic variants. Law Hum. Behav. 34, 150. doi: 10.1007/s10979-009-9175-y

Zeidner, M., Hadar, D., Matthews, G., and Roberts, R. D. (2013). Personal factors related to compassion fatigue in health professionals. Anxiety Stress Coping 26, 595-609. doi: 10.1080/10615806.2013.777045

Zeidner, M., Matthews, G., and Roberts, R. D. (2009). What We Know About Emotional Intelligence: How It Affects Learning, Work, Relationships, and Our Mental Health. Cambridge, MA: MIT Press.

Zeigler-Hill, V., Holden, C. J., Southard, A. C., Noser, A. E., Enjaian, B., and Pollock, N. C. (2016). “The dark sides of high and low self-esteem," in The Dark Side of Personality: Science and Practice in Social, Personality, and Clinical Psychology, eds V. Zeigler-Hill and D. K. Marcus (Washington DC, US: American Psychological Association), 325-340.

Zhang, W., Zou, H., Wang, M., and Finy, M. S. (2015). The role of the Dark Triad traits and two constructs of emotional intelligence on loneliness in adolescents. Pers. Individ. Dif. 75, 74-79. doi: 10.1016/j.paid.2014.10.025

Conflict of Interest Statement: The authors declare that the research was conducted in the absence of any commercial or financial relationships that could be construed as a potential conflict of interest.

Copyright (c) 2016 Davis and Nichols. This is an open-access article distributed under the terms of the Creative Commons Attribution License (CC BY). The use, distribution or reproduction in other forums is permitted, provided the original author(s) or licensor are credited and that the original publication in this journal is cited, in accordance with accepted academic practice. No use, distribution or reproduction is permitted which does not comply with these terms. 